\title{
COMPARISON OF THE GENERAL FITNESS LEVEL IN JUNIOR KAYAKERS WITH DIFFERENT SPORTS LEVEL
}

\author{
Mateusz Rynkiewicz, 1, A, B, C, D Piotr Żurek, 2, B Jacek Biernacki,, ${ }^{3, \text { B }}$ Karolina Pokrywka, 3, B \\ Tadeusz Rynkiewicz ${ }^{4}$, A, E
}

\author{
${ }^{1}$ University of Zielona Góra, Zielona Góra, Poland \\ 2 University School of Physical Education, Gorzów Wlkp. Poland \\ ${ }^{3}$ Mieszko I College of Education and Administration, Poznań, Poland \\ ${ }^{4}$ The Jacob of Paradies University, Gorzów Wlkp., Poland, Department of Tourism and Public Health \\ ${ }^{\text {A }}$ Study Design; ${ }^{\mathrm{B}}$ Data Collection; ${ }^{\mathrm{C}}$ Statistical Analysis; ${ }^{\mathrm{D}}$ Manuscript Preparation; ${ }^{\mathrm{E}}$ Funds Collection
}

\author{
Address for corpespondence: \\ Mateusz Rynkiewicz \\ University of Zielona Góra, Department of Medicine and Health Science \\ Institute of Sport and Health Promotion \\ Wyspiańskiego 58, 65-178 Zielona Góra, Poland \\ E-mail: m.rynkiewicz@wInz.uz.zgora.pl
}

\begin{abstract}
Ahstract The objectives of this study were to see if the general performance of kayakers depends on the level of their specific preparation and to identify the parameters of general preparedness that determine specific preparation. The subjects were divided into 3 groups on the basis of the result of a specific test: paddling over a 2,000-m distance. Group 2 included kayakers whose paddling time did not exceed \pm 1 SD for the whole sample, while group 1 included the best athletes with paddling times shorter than -1 SD and group 3 individuals who needed more than +1 SD to cover the 2,000-m distance. The study included 55 junior flatwater kayakers, represented various sports classes. All athletes manifested a similar level of endurance running, power and endurance pull and push barbell, $30 \mathrm{~m}$ running tests. The only differing characteristic between all groups was the level of asymmetry in distance of ball throw from sitting position of at 29,45 and $66 \%$ in each group and paddling for $2,000 \mathrm{~m}$ time. All athletes manifested a similar level of general fitness preparation. The only differing characteristic between all groups was the level of asymmetry in distance of ball throw from a sitting position.
\end{abstract}

Key words kayaking, determination of sports results, motor abilities, power, endurance, asymmetry

\section{Introduction}

Kayaking is a very popular type of physical activity, both in its recreational form and as a sports discipline. The latter has been included in the Olympic program since 1936. Currently, there are two types of kayaking in Olympic competition: flatwater kayaking and kayak slalom. 
Athletes who practice flatwater kayaking should have high levels of general preparation in terms of both aerobic (Van Someren, Phyllips, Palmer, 1999) and anaerobic (Bishop, 2000; Van Someren Oliver, 2001) capacity as well as adequate muscle strength. The latter should refer not only to maximum strength but also to strength endurance and power (Akca, Muniroglu, 2008; Rynkiewicz, Rynkiewicz, Żurek, 2014), primarily for the upper body (Tesch, 1993), but also for the trunk and core (Fekete, Coach, 1998; Fry, Morton, 1991). Furthermore, the athletes should master a specific paddling technique (Begon, Colloud, 2007; Fleming, Donne, Fletcher, 2012; Fleming, Donne, Fletcher, Mathony, 2012), also under unstable conditions (Rynkiewicz, Starosta, 2011), this may be particularly challenging, especially in the case of extreme fatigue. Therefore, improvement of body balance is another vital component of kayakers training (Rynkiewicz et al., 2014).

Such complex preparation is not possible without identifying the key determinants of successful performance. Analysis of our preceding research findings (in press), showed that the results of most general fitness tests conducted in 14- to 18-year-old kayakers correlated significantly with the time they required to cover a race distance. This observation prompted the study of the characteristics that distinguish elite kayakers from other athletes.

A number of papers dealing with general preparation of kayakers have been published to date (Akca, Muniroglu, 2008; Rynkiewicz et al., 2014, Van Someren, Palmer, 2003; Mckean, Burkett, 2010), however, aside from morphological structure (Ackland, Ong, Kerr, Ridge, 2003), no other factors that distinguish the preparation of high-level kayakers from that of other athletes have been identified. Moreover, many published studies included solely young kayakers (Rynkiewicz et al., 2014), or only individuals with low levels of specific preparation (Akca, Muniroglu, 2008).

Comparison of general preparation shown by kayakers from various performance categories would help their coaches to identify appropriate training objectives and could facilitate the development of multi-year training plans. However, such research may be challenging owing to limited availability and the generally low number of athletes being eligible for testing. Furthermore, such athletes devote most of their time to specific training especially paddling, and therefore, their coaches are reluctant to subject them to additional tests. On the basis of published data and our own research findings, the following were identified as the objectives of this study:

1. To see if general performance, power and endurance barbell pull and push, $30 \mathrm{~m}$ run test, $1,500 \mathrm{~m}$ run test and ball throw distance, of kayakers depends on the level of their 2,000 $\mathrm{m}$ kayak paddling preparation.

2. To identify the parameters of general preparedness that determine good specific preparation.

\section{Methods}

\section{Participants}

The study included 55 junior flatwater kayakers with a mean age of $17.49 \pm 0.5$ years, mean body height of $178.1 \pm 6.8 \mathrm{~cm}$, mean body weight of $76.3 \pm 6.8 \mathrm{~kg}$ and body mass index of $24.0 \pm 1.7 \mathrm{~kg} / \mathrm{m}^{2}$. The participants represented various sports classes, from II to master national class, including members of the National Junior Team. All procedures of this study were approved by the Local Ethics Committee at the Karol Marcinkowski University of Medical Sciences in Poznań, Poland. The experiments reported in the manuscript were performed in accordance with the ethical standards of the Helsinki Declaration. The legal guardians of the participants signed an informed consent form.

The subjects were divided into 3 groups on the basis of the result of a specific test: paddling over a 2,000-m distance. Group 2 included kayakers whose paddling time did not exceed \pm 1 SD for the whole sample, while group 
1 included the best athletes with paddling times shorter than -1 SD and group 3 individuals who needed more than +1 SD to cover the 2,000-m distance. The study subjects represented ca. $80 \%$ of all actively training Polish kayakers aged 16-17 years. All athletes included in group 1 were members of the Polish national team, and most of them participated in world and European championships during the competitive season covered by the study.

\section{Procedures}

The study was conducted in April 2013, and included a nationwide training camp. The results of a competition held during the camp constituted the basis for qualifying for the National Junior Team, which guaranteed us both a high level of motivation and optimal disposition of the athletes.

\section{Measurpes}

The first test was paddling in a kayak for a distance of 2,000 m (P2000). The athletes started one at a time, with a one-minute interval between the athletes. The first kayaker was the athlete who achieved the best score during a previous training camp. Competitors paddled in sports kayaks (K-1) in accordance with the rules of the International Canoe Federation. The weather was calm on the day of the competition and the wind speed was 1.5 $\mathrm{m} / \mathrm{s}$ parallel to the direction of the test.

Three hours after paddling, the athletes completed a series of general fitness tests. Athletes had at least 10 minutes of individual warm up, and a minimum of 5 minutes of rest between tests. The tests were conducted in a gym. The first test was the distance of a ball throw. The test was performed in two positions: first, in a sitting position, facing the area to which the ball was to be thrown, separately for the right (TSR) and left hand (TSL), and then in a standing position, also separately for the right (TRR) and left hand (TRL). The athletes were allowed to use a 3-m run-up during the second test. We measured the distance of the throw and recorded the ability to throw the ball forward within the boundaries of a 2-m wide track. The throw tests were used to determine the level of dynamic power. The exercise was performed twice and the better result was recorded. In analysing the result of throws, we calculated the asymmetry coefficient.

Next, athletes performed a 30-m run (R30). The test was performed to determine general dynamic speed potential. Time was measured using a Witty timing system (Microgate, Italy). Athletes started from a steady position $50 \mathrm{~cm}$ behind the timing gate. The athletes were allowed to start the run at a freely selected time point. The recorded running time was used to calculate mean running velocity. Moreover, momentum was calculated as the product of the athlete's body weight and mean running velocity (PR30).

After a series of ball throw and running speed tests, athletes went to a gym and prepared to perform a test to determine maximal velocity of movement during weightlifting exercise. We used the Tendo Weightlifting Analyzer (Slovakia) to determine the movement velocity of a barbell during the bench Press (Push P) and the bench Pull (Pull P). Exercises were performed with 2-minute intervals. Each participant performed a series of six repetitions of each exercise in the shortest possible time; the load corresponded to one-half of the athlete's body weight $\pm 2.5 \mathrm{~kg}$. We recorded the maximal average power of the one best repetition from series of six.

After the power test, the athletes performed the bench Pull (Pull E) and the bench Press (Push E) exercises for strength endurance determination (Akca, Muniroglu, 2008). We used a device which measures the distance of barbell, based on the movement of a cord connected to the rotary encoder. The results were displayed with an accuracy of $0.1 \mathrm{~cm}$. They performed the bench pull first, followed by a 30-min break, and then the bench press. 
The test involved a load corresponding to one-half of the athlete's body weight $\pm 2.5 \mathrm{~kg}$. The athletes repeated the exercise as many times as possible for up to $120 \mathrm{~s}$. To determine the amount of work performed, a recording device registered the distance covered by the barbell during each repetition with $0.01 \mathrm{~m}$ precision.

After the strength test, competitors had a 2-hour break and then started the running test (R1500) at a track and field stadium. The athletes ran a distance of $1,500 \mathrm{~m}$ in the shortest time possible. The competitors ran in groups of 15 , and a standard chronometer was used to measure the time. This test was conducted to measure the general level of endurance. Momentum was calculated as the product of the athlete's body weight and mean running velocity (PR1500).

\section{Statistical methods}

The study hypothesis was verified with a number of statistical methods. First, the mean and standard deviation were calculated. The Kolmogorov-Smirnov test was used to check the normal distribution of data. The asymmetry coefficient were calculated using the following formula:

where:

$$
W A=\frac{X_{p}-X_{l}}{\frac{\left(X_{p}+X_{l}\right)}{2}} \times 100 \%
$$

$$
\begin{aligned}
& W A \text { - asymmetry coefficient, } \\
& X_{p} \text { - right side throw distance, } \\
& X_{l} \text { - left side throw distance. }
\end{aligned}
$$

In the analysis, we used only the absolute values of the coefficients of asymmetry. We use the level of asymmetry in the distance of the alternate hand seated ball throw (ATS) and stand ball throw (ATR). Tukey Post-Hoc one-way ANOVA test for different group size was used to compare differences between groups. All the statistical analyses were conducted with a Statistica 9.0 package (StatSoft Inc. 1984-2011, license no. AXAP012D837210AR-7).

\section{Resullts}

The times, needed to cover the 2,000-m distance, achieved by subjects in group 1 (502.5 s), were significantly shorter that those of athletes in groups 2 and 3 (respectively $532.1 \mathrm{~s}$ and $571.8 \mathrm{~s}$ ). Also, the paddling times of kayakers in group 2 were significantly shorter than those of athletes in group 3 . These results confirmed the accuracy of the criterion we used to stratify the athletes into 3 groups showing different levels of performance.

Subsequently, we checked for potential differences in the levels of general preparation shown by athletes in the different groups (Table 1). We did not find any significant intergroup differences in the results of general preparation tests except in (ATS), which was significantly different between athletes in groups 1 and 3 . The lowest values for ATS and ATR were achieved by subjects in group 1 (29 and 31\%, respectively), followed by individuals in group 2 (45 and 43\%, respectively) and group 3 (66 and 59\%, respectively) (Figure 1). 
Table 1. The results of performed tests

\begin{tabular}{|c|c|c|c|c|c|c|}
\hline & \multicolumn{6}{|c|}{ Mean, $\pm S D$, min-max } \\
\hline & \multicolumn{6}{|c|}{ number of group } \\
\hline & \multicolumn{2}{|c|}{1} & \multicolumn{2}{|c|}{2} & \multicolumn{2}{|c|}{3} \\
\hline & $\mathrm{M} \pm \mathrm{SD}$ & $\min -\max$ & $\mathrm{M} \pm \mathrm{SD}$ & $\min -\max$ & $\mathrm{M} \pm \mathrm{SD}$ & $\min -\max$ \\
\hline Weight (kg) & $78.3 \pm 4.5$ & $73.0-85.0$ & $75.5 \pm 7.4$ & $64.3-91.0$ & $77.3 \pm 6.2$ & $67.0-85.0$ \\
\hline Height $(\mathrm{cm})$ & $180.6 \pm 2.2$ & 177-184 & $177.8 \pm 6.1$ & $167.0-184.0$ & $176.4 \pm 5.4$ & $169.0-183.0$ \\
\hline $\mathrm{BMI}\left(\mathrm{kg} / \mathrm{m}^{2}\right)$ & $24.0 \pm 1.0$ & $22.0-25.0$ & $23.9 \pm 1.8$ & $20.6-25.0$ & $24.8 \pm 1.7$ & $22.0-28.0$ \\
\hline P2000 (s) & $502.5 \pm 8.9{ }^{*} £$ & $484.0-510.0$ & $532.1 \pm 11.8^{*} ¥$ & $513.2-510.0$ & $571.8 \pm 13.5 £ ¥$ & $556.0-592.0$ \\
\hline Pull E (kgm) & $989.3 \pm 335.9$ & $553.0-1435.0$ & $972.4 \pm 238.6$ & $580.0-1435.0$ & $892.3 \pm 225.3$ & $502.0-1240.0$ \\
\hline Push E (kgm) & $938.1 \pm 275.1$ & $474.0-1220.0$ & $988.0 \pm 276.4$ & $458.0-1220.0$ & $994.4 \pm 242.8$ & $694.0-1320.0$ \\
\hline Push P (W) & $465.0 \pm 49.1$ & $361.0-510.0$ & $469.7 \pm 60.8$ & $353.0-627.0$ & $505.6 \pm 57.3$ & $426.0-585.0$ \\
\hline Pull P (W) & $518.0 \pm 73.9$ & $409.0-636.0$ & $525.3 \pm 57.7$ & $427.0-636.0$ & $539.6 \pm 59.9$ & $474.0-627.0$ \\
\hline PR30 (kgm/s) & $510.2 \pm 43.7$ & $457.0-587.0$ & $480.8 \pm 48.7$ & $387.0-595.0$ & $505.0 \pm 47.8$ & $418.0-561.0$ \\
\hline TSR (m) & $10.9 \pm 2.7$ & $6.0-14.0$ & $11.3 \pm 2.2$ & $6.0-16.0$ & $12.7 \pm 2.8$ & $9.0-17.0$ \\
\hline TSL (m) & $8.2 \pm 2.6$ & $5.0-13.0$ & $7.2 \pm 2.0$ & $3.0-13.0$ & $6.4 \pm 1.5$ & $5.0-8.0$ \\
\hline ATS (\%) & $29.0 \pm 50.0 £$ & $-50.0-70.0$ & $45.0 \pm 28.0$ & $-40.0-110.0$ & $66.0 \pm 15.0 £$ & $40.0-82.0$ \\
\hline $\operatorname{TRR}(\mathrm{m})$ & $19.9 \pm 5.1$ & $12.0-28.0$ & $21.0 \pm 3.8$ & $14.0-28.0$ & $22.6 \pm 3.1$ & $18.0-26.0$ \\
\hline TRL (m) & $14.4 \pm 4.1$ & $9.0-21.0$ & $13.5 \pm 2.4$ & $10.0-22.0$ & $12.4 \pm 3.0$ & $9.0-17.0$ \\
\hline ATR (\%) & $31.0 \pm 36.0$ & $-20.0-70.0$ & $43.0 \pm 23.0$ & $-30.0-80.0$ & $59.0 \pm 24.0$ & $30.0-97.0$ \\
\hline PR1500 (kgm/s) & $378.8 \pm 35.0$ & $327.0-424.0$ & $358.1 \pm 35.59$ & $271.7-454.0$ & $340.8 \pm 61.6$ & $231.0-406.0$ \\
\hline
\end{tabular}

* - statistically significant difference between group 1 and group $2 p<0.05$.

$£$ - statistically significant difference between group 1 and group $3 p<0.05$.

$¥-$ statistically significant difference between group 2 and group $3 p<0.05$.

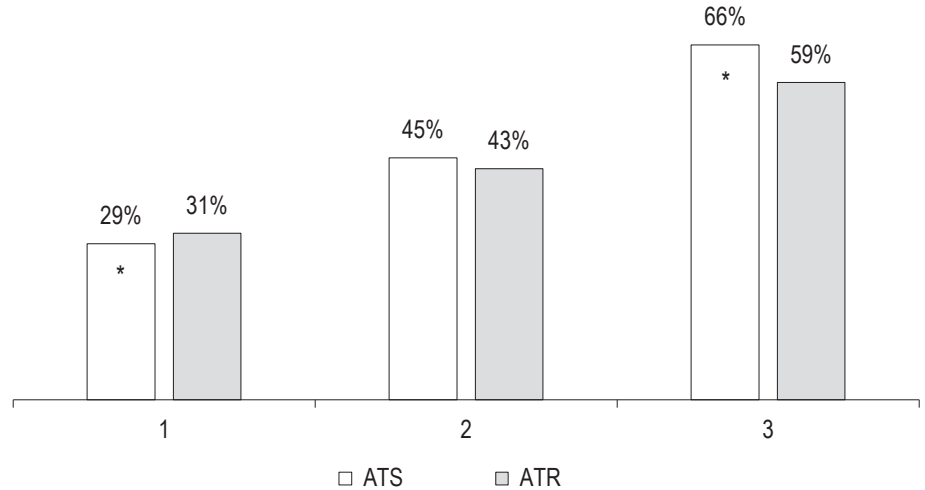

* - statistically significant difference between group 1 and group $3, p<0.05$

Figure 1. The mean level of ATS and ATR in a group of kayakers 


\section{Disculssion}

The study objectives were to see if general performance, power and endurance barbell pull and push, $30 \mathrm{~m}$ run test, 1,500 m run test and ball throw distance, of kayakers depends on the level of their 2,000 $\mathrm{m}$ kayak paddling preparation, and also to identify the parameters of general preparedness that determine good specific preparation.

Athletes in the three groups differed in terms of their performance in the 2,000-m paddling. However, we did not find any significant differences in the other parameters for the athletes examined. Kayakers in group 1 were nearly $4 \mathrm{~cm}$ taller and $1 \mathrm{~kg}$ heavier than subjects in group 3. Morphological characteristics of the athletes participating in this study were slightly different from those reported by other authors (Ackland et al., 2003; MišigojDyraković, Heimer, 1992), perhaps due to the relatively young age of our subjects.

Kayakers should have a high level of general preparation K.A. Van Someren et al. (1999), D. Bishop (2000), K.A. Van Someren, J.E. Oliver (2001), F. Akca, S. Muniroglu (2008), M. Rynkiewicz et al. (2014). The overall preparation level of our junior kayakers could be considered good and similar to reported by F. Akca, S. Muniroglu (2008), M. Rynkiewicz et al. (2014). Interestingly, contrary to our expectations, we did not find significant intergroup differences in terms of general preparation.

We observed some differences in the level of asymmetry in the distance of the alternate hand seated ball throw (Figure 1). Flatwater kayaking requires the involvement of the upper body, namely alternating right and left rotation of the trunk (Mann, Kearney, 1980). Therefore, kayakers should have an adequate upper body (Tesch, 1993), and trunk (Fekete, Coach, 1998) strength, and a high level of bilateral symmetry as well (Rynkiewicz, Starosta, 2011). Consequently, there is an apparent association between the upper trunk strength and athlete's performance (McKean, Burkett, 2010). According to McKean, Burkett (2010), kayakers have a limited range of motion in the shoulder joint. Limited shoulder flexibility and other differences in arm function are risk factors for injury in some disciplines, e.g., baseball (Donatelli et al., 2000) and volleyball (Kugler, 1996). Shoulder injuries are also the most common problem in kayaking (Edwards, 1993). The level of asymmetry in the distance of the alternate hand seated ball throw turned out to be the principal parameter contributing to the different performance of our kayakers in groups 1, 2 and 3 . This is consistent with the data published by other authors who emphasized the pivotal role of the upper body (Tesch, 1993; Mckean, Burkett, 2010; Mann, Kearney, 1980) and high symmetry level (Rynkiewicz, Starosta, 2011).

Most of the Polish population is characterised by the dominance of one body side over the other (Starosta, 2008). Movements performed with a dominant side are generally faster (Bryden, Key, 2002) and more precise (Hausmann, Kirk, Corballis, 2004). However, kayakers should have high levels of symmetry (Rynkiewicz, Starosta, 2011), which can be tested with the alternate hand seated ball throw. An athlete starts the test in a position similar to that during paddling in a kayak, and the throw requires appropriate rotation of the trunk combined with a dynamic movement of the arm. According to M. Rynkiewicz et al. (2014), a high level of motor coordination in stable body position is a determinant of paddling performance. Asymmetry results from poor communication between the two cerebral hemispheres (Sainburg, 2005) and biomechanical differences in the structures of the right and left body (Carey, Otto de Haart, 2001). Consequently, it can be concluded that the difference in performance of junior kayakers results from the variable development of their motor coordination.

K.A. Ericsson, R.T. Krampe, C. Tesch-Römer (1993) proposed a theory of deliberate practice where they assumed the necessity to use specific forms of training to the attainment of expertise. J. Baker, J. Côté, B. Abernethy (2003) and T. Hodge, J. Deakin (1998) reported a strong positive correlation between the hour of high 
quality training and sports achievement. However, researchers examining the early stages of development in elite athletes (Carlson, 1988; Côté, 1999; Hill, 1993), have reported that early specialisation as a child does not seem to be an essential ingredient for exceptional sports performance as an adult. According to P. Ward, N.J. Hodges, J.L. Starker, A.M. Williams (2002) elite soccer players did not specialise until after the age of 16. In sports practice, specific training stimuli are often implemented too early to achieve high performance of an athlete still at initial stages of his/her training. However, such approach may prevent further progress in the long term, which results in preterm stabilisation of an athlete's performance and his/her inability to develop (Barynina, Vaitsekhovskii, 1992). Excessive training without adequate recovery can lead to staleness and burnout (Henschen, 1998). This points to the pivotal role of a comprehensive training, especially aimed at the development of motor coordination and symmetry. According to L.D. Wiersman (2000), limited range of skills performed during early sports specialisation can limit overall motor skills development. An athlete subjected to such training will eventually show an appropriate level of strength and endurance under the demanding and unstable conditions of paddling in a kayak.

Unsurprisingly, the level of preparation demonstrated by our kayakers differed from that of the general population. Our study included elite junior kayakers who competed for positions on the Polish national team. All subjects were in their post-pubertal years; this period is characterised by stabilisation of motor skills and body structure. This may explain the lack of statistically significant differences in motor preparation between our athletes. In turn, the significant intergroup differences in symmetry level likely corresponded to the variable preparation of kayakers in terms of their coordination. Therefore, the level of symmetry and indirectly also motor coordination are crucial parameters determining the different performance of junior kayakers.

\section{Conclusions}

All athletes manifested a similar level of general fitness preparation. The only differing characteristic between all groups was the level of asymmetry in distance of ball throw from a sitting position.

It seems that the leading characteristic providing a high level of performance was the level of symmetrization and motor coordination.

\section{Acknowledgments}

The authors wish to thank coaches and athletes from Polish Canoe Federation for their help and participation in the research project. The authors report no conflicts of interest with this work. Funding for this project was provided by the grants no. 0031/RS1/2011/57 from Polish Ministry of Science and Higher Education.

\section{References}

Ackland, T.R., Ong, KB., Kerr, D.A., Ridge, B. (2003). Morphological characteristics of Olympic sprint canoe and kayak paddlers. Journal of Science \& Medicine in Sport, 6, 285-294.

Akca, F., Muniroglu, S. (2008). Anthropometric-somatotype and strength pro- files and on-water performance in Turkish elite kayakers. IJASS, 20, 22-34.

Baker, J., Côté, J., Abernethy, B. (2003). Sport specific training, deliberate practice and the development of expertise in team ball sports. Journal of Applied Sport Psychology, 15, 12-25.

Barynina, I.I., Vaitsekhovskii, S.M. (1992). The aftermath of early sports specialization for highly qualified swimmers. Fitness and Sports Review International, 27 (4), 132-133. 
Begon, M., Colloud, F. (2007). A kayak ergometer using a sliding trolley to reproduce accurate on-water mechanical conditions. J. Biomech, 40, 439.

Bishop, D. (2000). Physiological predictors of flat-water kayak performance in women. European Journal of Applied Physiology, 82, 91-97.

Bryden, P.J., Kay, C.A. (2002). Hand preference in simultaneous unimanual tasks: A preliminary examination. Brain and Cognition, 48, 284-287.

Carey, D.P., Otto de Haart E.G. (2001). Hemispatial differences in visually guided aiming are neither hemispatial nor visual. Neuropsychology, 39, 885-894.

Carlson, R.C. (1988). The socialization of elite tennis players in Sweden: An analysis of players' backgrounds and development. Sociology of Sport Journal, 5, 241-256.

Côté, J. (1999). The influence of the family in the development of talent in sports. The Sport Psychologist, 13, 395-417.

Donatelli, R., Ellenbecker, T., Ekedahl, S., Wilkes, J.S., Kocher, K., Adam, J. (2000). Assessment of shoulder strength in professional baseball pitchers. J Orthop Sports Phys Ther, 30, 544-551.

Edwards, A. (1993). Injuries in kayaking. Sport Health, 11, 8-11.

Ericsson, K.A., Krampe, R.T., Tesch-Römer, C. (1993). The role of deliberate practice in the acquisition of expert performance. Psychological Review, 100, 363-406.

Fekete, M., Coach, H. (1998). Periodized strength training for sprint kayaking/canoeing. Strength Cond, 20, 8-14.

Fleming, N., Donne, B., Fletcher, D. (2012). Effect of kayak ergometer elastic tension on upper limb emg activity and 3d kinematics. Journal of Sport Science and Medicine, 11, 430-437.

Fleming, N., Donne, B., Fletcher, D., Mahony, N. (2012). A biomechanical assessment of ergometer task specificity in elite flatwater kayakers. Journal of Sport Science and Medicine, 11, 16-25.

Fry, R., Morton, A. (1991). Physiological and kinanthropometric attributes of elite flatwater kayakists. Med Sci Sports Exerc, 23, 1297.

Hausmann, M., Kirk, I.J., Corballis, M.C. (2004). Influence of task complexity on manual asymmetries. Cortex, 40, 103-110.

Henschen, K.P. (1998). Athletic staleness and burnout: Diagnosis, prevention, and treatment. In: J.M. Williams (ed.), Applied sport psychology: Personal growth to peak performance, (pp. 398-408). CA: Mayfield, Mountain View.

Hill, G.M. (1993). Youth sport participation of professional baseball players. Sociology of Sport Journal, 10, 107-114.

Hodge, T., Deakin, J. (1998). Deliberate practice and expertise in the martial arts: The role of context in motor recall. Journal of Sport \& Exercise Psychology, 20, 260-279.

Kugler, A. (1996). Muscular imbalance and shoulder pain in volleyball attackers. Br J Sports Med, 30, 256-259.

Mann, R., Kearney, J. (1980). A biomechanical analysis of the Olympicstyle flatwater kayak stroke. Med. Sci. Sports Exerc, 12, 183-188.

McKean, M.R., Burkett, B. (2010). The relationship between joint range of motion, muscular strength, and race time for sub-elite flat water kayakers. Journal of Science and Medicine in Sport, 13, 537-542.

Mišigoj-Dyraković, M., Heimer, S. (1992). Characteristics of the morphological and functional status of kayakers and canoeists. J. Sport Med. Phys. Fitness, 32, 45-50.

Rynkiewicz, M., Rynkiewicz, T., Żurek, P. (2014). Evaluation of factors affecting sports performance among junior athletes in kayaking. Medicina dello Sport, 67, 555-568.

Rynkiewicz, M., Starosta, W. (2011). Asymmetry of paddling technique, its selected conditions and changeability in highly advanced kayakers. Poznań-Warszawa: AWF, International Association of Sport Kinetics (IASK).

Sainburg, R.L. (2005). Handedness: Differential specializations for control of trajectory and position. Exerc. Sport Sci. Rev, 33, 206-213.

Starosta, W. (2008). Stronne zróżnicowanie techniki ćwiczeń zawodników rozmaitych dyscyplin sportu. Supraśl: Wyższa Szkoła Wychowania Fizycznego i Turystyki.

Tesch, P. (1993). Physiological characteristics of elite kayak paddlers. Can J Appl Sport Sci, 8, 87-91.

Van Someren, K.A., Oliver, J.E. (2001). The efficacy of ergometry determined heart rates of flatwater kayak training. International Journal of Sports Medicine, 23, 28-32.

Van Someren, K.A., Palmer, G.S. (2003). Predictor of 200 m, sprint kayaking performance. Canadian Society for exercise Physiology, $28,505-517$. 
Van Someren, K.A., Phillips, G.R.W., Palmer, G.S. (1999). Comparison of physiological responses to open water kayaking and kayak ergometry. International Journal of Sports Medicine, 21, 200-204.

Ward, P., Hodges, N.J., Starkes, J.L., Williams, A.M. (2007). The road to excellence: deliberate practice and the development of expertise. High Ability Studies, 18 (2), 119-153. DOI: 10.1080/13598130701709715.

Wiersman, L.D. (2000). Risks and benefits of youth sport specialization: Perspectives and recommendations. Pediatric Exercise Science, 12, 13-22.

Cite this article aS: Rynkiewicz, M., Żurek, P., Biernacki, J., Pokrywka, K., Rynkiewicz, T. (2019). Comparison of the General Fitness Level in Junior Kayakers with Different Sports Level. Central European Journal of Sport Sciences and Medicine, 2 (26), 57-65. DOI: 10.18276/cej.2019.2-06. 